Biochimica et Biophysica Acta, 368 (1974) 61-70

(C) Elsevier Scientific Publishing Company, Amsterdam - Printed in The Netherlands

BBA 46808

\title{
RELATION OF MEMBRANE STRUCTURAL CHANGES TO ENERGY SPILLOVER IN OAT AND SPINACH CHLOROPLASTS: USE OF FLUORESCENCE PROBES AND LIGHT SCATTERING
}

\section{DAVID L. VANDERMEULEN and GOVINDJEE}

Department of Botany and Physiology and Biophysics, University of Illinois, Urbana, Ill. 61801 (U.S.A.) (Received April 10th, 1974)

\section{SUMMARY}

The antagonism observed by Gross and Hess (Gross, E. and Hess, S. C. (1973) Arch. Biochem. Biophys. 159, 832-836) in the effect of monovalent and divalent cations on energy spillover between Photosystems I and II, as indicated by chlorophyll $a$ fluorescence, was confirmed in spinach. Significant differences with oats, peas and lettuce were found using the same low salt method of preparation: the response to $\mathrm{Na}^{+}$and $\mathrm{Ca}^{2+}$ was reversible, $\mathrm{Ca}^{2+}$ alone, when added first, produced a large $(85 \%)$ increase in the variable portion of the chlorophyll $a$ fluorescence transient or the steady-state fluorescence, and $\mathrm{Ca}^{2+}$ not only fully restored a $\mathrm{Na}^{+}$induced inhibition of $680 \mathrm{~nm}$ fluorescence, but brought it above the original level. The fluorescence probes 1-anilinonaphthalene-8-sulfonate and $N$-phenyl-1-naphthylamine showed a rapid and a slower response, respectively, to the addition of mono- or divalent cations. Neither the structural changes responsible for the probe data, nor those leading to the measured cation stimulated changes in $90^{\circ}$ light scattering could be precisely equated with any alteration of conformation involved in the chlorophyll spillover events.

\section{INTRODUCTION}

The role of cations in regulating the physical structure of the photosynthetic membrane has been a question of increasing concern in recent times. Gross and Hess [1] showed that monovalent cations decrease chlorophyll $a$ fluorescence at $680 \mathrm{~nm}$ that was subsequently reversed by divalent cations in spinach chloroplasts; these data were interpreted as reflecting changes in the spillover of excitation energy between weakly fluorescent Photosystem I and strongly fluorescent Photosystem II. (For reference to earlier literature see Mohanty et al. [2].) Since it was probable that some sort of conformational or configurational change of the thylakoid membrane or one or more of their components could be responsible for such a change, we have investi-

Abbreviations: DCMU, 3-(3,4-dichlorophenyl)-1,1-dimethylurea; Auramine O, tetramethyldiaminodiphenylketoimine $\cdot \mathbf{H C l}$; $\mathrm{ANS}^{-}, 1$-anilinonaphthalene-8-sulfonate; NPN, $N$-phenyl-1-naphthylamine. 
gated this possibility. This paper reports results of the response of chlorophyll $a$ fluorescence to mono- and divalent cations along with changes in extrinsic probe fluorescence and $90^{\circ}$ light scattering. Light scattering at $90^{\circ}$ has been previously used as an indicator of "macro" structural events in photosynthetic systems [3], while the fluorescence of the added probe molecules is used as a monitor of more local membrane phenomena (Murakami and Packer [4]; also see Radda and Vanderkooi [5] for further discussion of probes). In this paper, the probes 1-anilinonaphthalene-8sulfonate (ANS ${ }^{-}$), $N$-phenyl-1-naphthylamine (NPN) and tetramethyldiaminodiphenylketoimine $\cdot \mathrm{HCl}$ (Auramine $\mathrm{O}$ ) were employed since their fluorescence is highly sensitive to the environment in which they are located. Ample evidence exists to assert that water-soluble $\mathrm{ANS}^{-}$binds at the membrane-water interface region [6-8], and its binding is sensitive to surface charges $[4,9,10]$. NPN, on the other hand, being neutral and largely water insoluble, is a probe of the more hydrophobic regions of the membrane [11]. The results reported here suggest to us that the control cations exert on the intersystem energy distribution may not be mediated by the "large scale" alteration of the membrane's dimensions, but rather by a more localized and specific cation regulated "transfer switch", similar to the concept proposed by Seely [12].

\section{EXPERIMENTAL METHODS}

Unless otherwise indicated, spinach (Spinacea oleraceae), oat (Avena sativa), pea (Pisum sativum) or lettuce (Lactuca sativa) chloroplasts were prepared in low ionic strength medium and suspended in concentrated form (1-2 $\mathrm{mg}$ chlorophyll/ml) in $350 \mathrm{mM}$ sucrose [13]. When transferred to the low ionic strength reaction mixture a moderate osmotic shock occurs and in the absence of salts the thylakoid membranes are not tightly stacked (hereafter referred to as "washed chloroplasts").

The low salt buffer used in most experiments of this paper consisted of $100 \mathrm{mM}$ sucrose and sufficient Tris base (approx. $0.17-0.20 \mathrm{mM}$ ) to titrate chloroplasts to about $\mathrm{pH} 8$; the effects did not vary noticeably in the $\mathrm{pH}$ range $7.5-8.5$. 3-(3,4Dichlorophenyl)-1,1-dimethylurea (DCMU), when added, insured that the Photosystem II traps were closed. Chlorophyll concentration was deter mined by the method of MacKinney [14] using a Cary 14 spectrophotometer. 3-ml sampl es were placed in $1-\mathrm{cm}$ fluorescence cells. Additions of chemicals with Hamilton mi crosyringes were confined to volume changes of about $3 \%$ or less; solvent controls were done to eliminate the possibility of mixing artifacts.

Fluorescence and light scattering measurements were recorded at $90^{\circ}$. Excitation light, originating from a Hanovia $\mathrm{Hg}-\mathrm{Xe}$ lamp $(200 \mathrm{~W})$, was passed through a Bausch and Lomb monochromator (band width, $6.4 \mathrm{~nm} / \mathrm{mm}$ of slit opening). Actinic (saturating) light, supplied by a tungsten filament (G.E. $6 \mathrm{~V}$ lamp), was filtered through Corning C.S. 3-73 plus C.S. 4-96 glass filters. Both excitation and actinic beams were at $90^{\circ}$ relative to the axis of the observation monochromator. Steady-state chlorophyll fluorescence (also excited with blue actinic light) was passed through a C.S. $2-59$ red filter and monitored at $680 \mathrm{~nm}$.

Probe fluorescence was excited at $365 \mathrm{~nm}$ and monitored at the emission maximum; two C.S. 7-60 filters were used with the monochromator to eliminate "second order" and other artifacts. Fluorescence was measured with an RCA C7268 photomultiplier, a Keithley picoammeter, and a Moseley (2D-2) Autograf or an Esterline 
Angus recorder. In emission spectra of chloroplast suspension, the inner filter effect was accounted for with the correction factor $X=\operatorname{antilog}\left(A_{\mathrm{a}}+A_{\mathrm{e}}\right) / 2$ (see Chignell [15]), where subscripts a and e refer to the wavelengths of excitation and emission, respectively.

Absorption measurements were made with a Bausch and Lomb (Spectronic 505) recording spectrophotometer equipped with an integrating sphere attachment to minimize scattering artifacts. For $90^{\circ}$ light scattering measurements, the spectrofluorometer described above was employed by dialing in the same wavelengths on the excitation and observation monochromators.

Chlorophyll $a$ fluorescence transients were measured at $685 \mathrm{~nm}$ with the spectrofluorometer as described by Munday and Govindjee [16]; constant (" $O$ ") fluorescence levels were measured at about $50 \mathrm{~ms}$ and the variable (" $P$ ") levels at $60 \mathrm{~s}$, after the onset of tungsten exciting light passed through C.S. 3-73 plus C.S. 4-96 glass filters.

For residual ion concentration measurements, chloroplasts, prepared in low salt, containing approximately $1 \mathrm{mg}$ chlorophyll, were incubated in $3 \%$ trichloroacetic acid. After centrifugation to remove all denatured material, the supernatant was collected for the determination of ion content with a Jarrell-Ash (82-700) atomic absorption spectrometer; $\mathrm{K}^{+}$was monitored at $7665 \AA$, and $\mathrm{Mg}^{2+}$ at $2852 \AA$.

\section{RESULTS}

\section{(1) Chlorophyll a fluorescence}

In washed spinach chloroplasts, a monovalent cation-induced decrease of chlorophyll fluorescence is followed by a divalent cation-induced increase but the

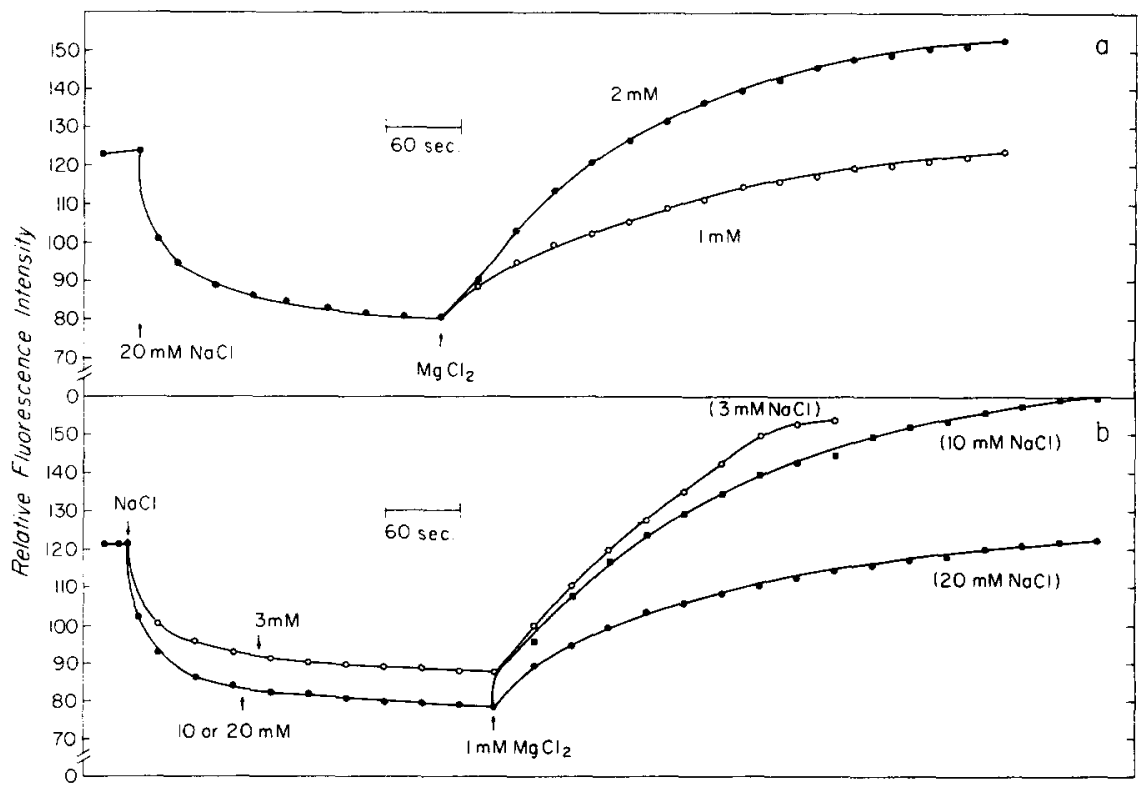

Fjg. 1. Time course of cation induced changes in chlorophyll a fluorescence. Oat chloroplast suspension containing $5 \mu \mathrm{g}$ chlorophyll/ml, $5 \mu \mathrm{M} \mathrm{DCMU}$ in low salt buffer (see Experimental Methods). 
addition of $\mathrm{Mg}^{2+}$ or $\mathrm{Ca}^{2+}$ is unable to completely restore the original fluorescence level. In washed oat chloroplasts, however, even with as much as $20 \mathrm{mM} \mathrm{NaCl}$ added first (above the saturating concentration for the $\mathrm{Na}^{+}$induced decrease), $\mathrm{MgCl}_{2}$ (or $\left.\mathrm{CaCl}_{2}\right)$ brings the fluorescence well above the original level (1.25 to 1.50 times; Fig. 1). We have also seen this with a $30 \mathrm{mM} \mathrm{NaCl}$ and $3 \mathrm{mM} \mathrm{CaCl}$ combination, where the final increase was little different than when only $6.7 \mathrm{mM} \mathrm{NaCl}$ was added first. As the concentration of $\mathrm{NaCl}$ is increased (Fig. 1b), it appears that $\mathrm{Mg}^{2+}$ is prevented from attaching properly to its binding site (either due to competition or change in conformation, see Discussion); thus the divalent cations are unable to fully augment the Photosystem II fluorescence. In contrast with the results in spinach, large cation stimulated increase in Photosystem II fluorescence is also observed in the absence of $\mathrm{Na}^{+}$, i.e. when $\mathrm{Ca}^{2+}$ (optimum concentration: 2-3 mM) is added first (Fig. 2).

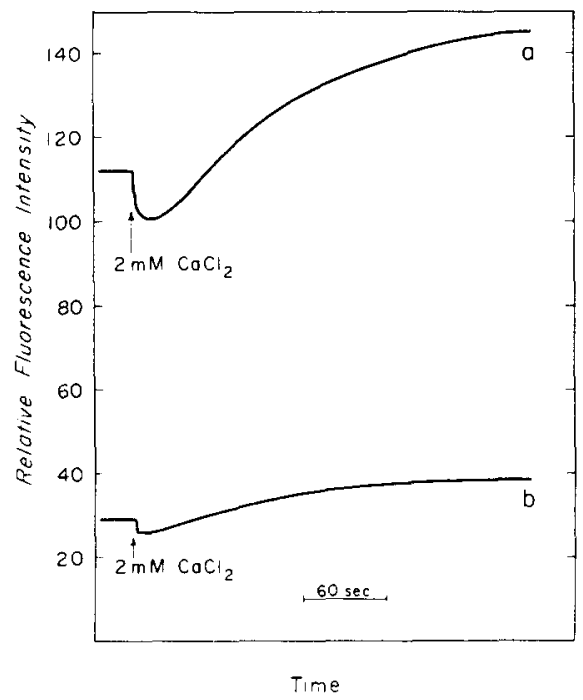

Fig. 2. Time course of $\mathrm{Ca}^{2+}$ induced changes in chlorophyll $a$ fluorescence in washed oat chloroplasts. Conditions as in Fig. 1. Curve $b$ is as curve a with the actinic light passed through a $25 \%$ transmission filter.

Since it might be contested that there are more "trapped" monovalent ions in the oat preparation, thus producing a depressed initial fluorescence intensity, the residual concentrations of tightly bound ions were checked in washed spinach and oat chloroplasts (same procedure for both species, see Experimental Methods). In spinach, the concentrations of $\mathrm{K}^{+}$and $\mathrm{Mg}^{2+}$ were found to be 32 and $34 \mathrm{ng} / \mu \mathrm{g}$ chlorophyll, respectively; in oats, values of 12 and $24 \mathrm{ng} / \mu \mathrm{g}$ chlorophyll were obtained for $\mathrm{K}^{+}$and $\mathrm{Mg}^{2+}$, respectively. Thus, within the limitations of this type of measurement, no differences in the residual content of mono- and divalent cations in these two species can explain the $\mathrm{Ca}^{2+}$ induced chlorophyll fluorescence increase. Results for $\mathrm{Na}^{+}$and $\mathrm{K}^{+}$using flame-photometry were similar to the above $\mathrm{K}^{+}$data.

It is significant that data essentially identical to that presented above in Figs 1 and 2 for oats was also obtained when washed chloroplasts from peas and lettuce were used (not shown); spinach seems to be the exception. Gross and Hess [1] state that the "addition of $1 \mathrm{mM} \mathrm{CaCl}{ }_{2}$ had no effect under these conditions". We do see, 
though, that in spinach $3 \mathrm{mM} \mathrm{CaCl}_{2}$ gives an initial decrease (up to $10 \%$ ) as with oats, but there is only a small subsequent rise, unlike the large increase going above the original level in oats (Fig. 2). Gross and Hess [1] also saw that addition of $\mathrm{NaCl}$ after $\mathrm{CaCl}_{2}$ had no effect, which we can confirm with spinach. But in oats (this paper), this is not the case, for if non-saturating concentrations of either ion are utilized, the changes are reversible; this is true when either $\mathrm{CaCl}_{2}$ (presented below, Fig. 5d) or $\mathrm{NaCl}$ (not shown here) is added first. In spinach, Gross and Hess [1] found that 3.3 $\mathrm{mM} \mathrm{CaCl}{ }_{2}$ prevented the decrease in fluorescence at all $\mathrm{Na}^{+}$concentrations tested; with washed oat chloroplasts, we have seen that $\mathrm{NaCl}$ at $30 \mathrm{mM}$ can bring the fluorescence down, after the $\mathrm{Ca}^{2+}$ induced increase, even to the original intensity.

In order to better discern what role these ions are playing in the control of energy distribution, the chlorophyll fluorescence transient was examined. Fig. 3 shows

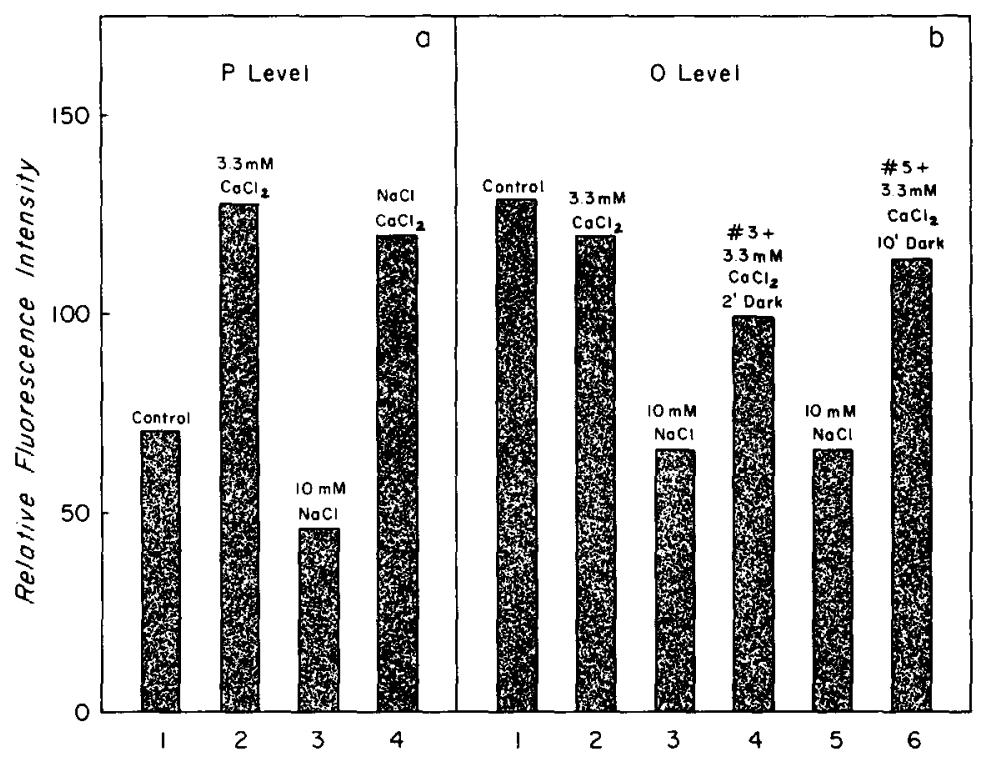

Fig. 3. Effects of $\mathrm{NaCl}$ and $\mathrm{CaCl}_{2}$ on the constant (" $O$ ") and variable (" $P$ ") levels of the chlorophyll fluorescence transient in washed oat chloroplasts. Conditions as in Fig. 1; relative intensity of $\mathbf{a}$ and $\mathbf{b}$ not to same scale. (See Experimental Methods for further details.)

the effects of added $\mathrm{NaCl}$ and $\mathrm{CaCl}_{2}$ on the " $O$ " and " $P$ " levels (representing the constant and variable portions of the transient, respectively; see Govindjee and Papageorgiou [17] for a review). At the " $P$ " level, the situation is similar to the changes in steady-state fluorescence already mentioned, $3.3 \mathrm{mM} \mathrm{CaCl}$ and $10 \mathrm{mM}$ $\mathrm{NaCl}$ yielding an $85 \%$ increase and $35 \%$ decrease, respectively; $\mathrm{NaCl}$ causes only a small reduction in the enhancement produced by $\mathrm{CaCl}_{2}$ under these conditions. At the " $O$ " level, $3.3 \mathrm{mM} \mathrm{CaCl}_{2}$ gives a small $(5-10 \%)$ decrease while $10 \mathrm{mM} \mathrm{NaCl}$ causes a much larger $(50 \%)$ depression in fluorescence intensity; $\mathrm{CaCl}_{2}$ added to the $\mathrm{NaCl}$ sample reverses the inhibition, the process being dependent on the time in the dark (see Experiments 4 and 6 of Fig. 3b). In spinach, Wydrzynski et al. (submitted for publication) have obtained similar data for the " $O$ " level, but they see no $\mathrm{Ca}^{2+}$ 
stimulated increase in the " $P$ " level. Thus, the differences are related to the variable part of the fluorescence, correlated with the photochemical or photophysical events in Photosystem II.

\section{(2) Extrinsic probe fluorescence}

To investigate the effects of sodium and calcium salts on different regions of the thylakoid membrane, probe fluorescence was examined in washed chloroplasts. If the contribution of "environmental constraint" to the position of the wavelength of maximum emission $\left(\lambda_{\max }^{\mathrm{f}}\right)$ is indeed small [18], then $\lambda_{\max }^{\mathrm{f}}$ for the probe in the membrane offers an indication of the relative dielectric constant of its surroundings (see Radda [19] for further discussion). For $\mathrm{ANS}^{-}, \lambda_{\max }^{\mathrm{f}}$ shifts from $530 \mathrm{~nm}$ in water to about $510 \mathrm{~nm}$ (uncorrected for photomultiplier and monochromator's spectral sensitivity) when bound to spinach chloroplasts; with NPN the shift is much larger, from 480 to $430 \mathrm{~nm}$. A comparison with our measurements on probe fluorescence as a function of ethanol concentration (not shown) allows us to suggest that the ANS ${ }^{-}$ and NPN binding sites have a micro-environment polarity something of the character of 35 and $100 \%$ ethanol, respectively. The chloroplast data, then, is qualitatively consistent with the placement of dye locations presented in the Introduction.

When either $\mathrm{NaCl}$ or $\mathrm{MgCl}_{2}$ is added to a preparation of washed chloroplasts there is a rapid, immediate increase in $\mathrm{ANS}^{-}$fluorescence intensity (Fig. 4a). The enhancement of $\mathrm{ANS}^{-}$emission as first $\mathrm{NaCl}$ and then $\mathrm{MgCl}_{2}$ are added to the thylakoid preparation appears to be saturated with the same range of concentrations as for the chlorophyll fluorescence response (about $10 \mathrm{mM}$ and $1-2 \mathrm{mM}$, for the mono- and divalent ions, respectively). Similar, but opposite changes are found with

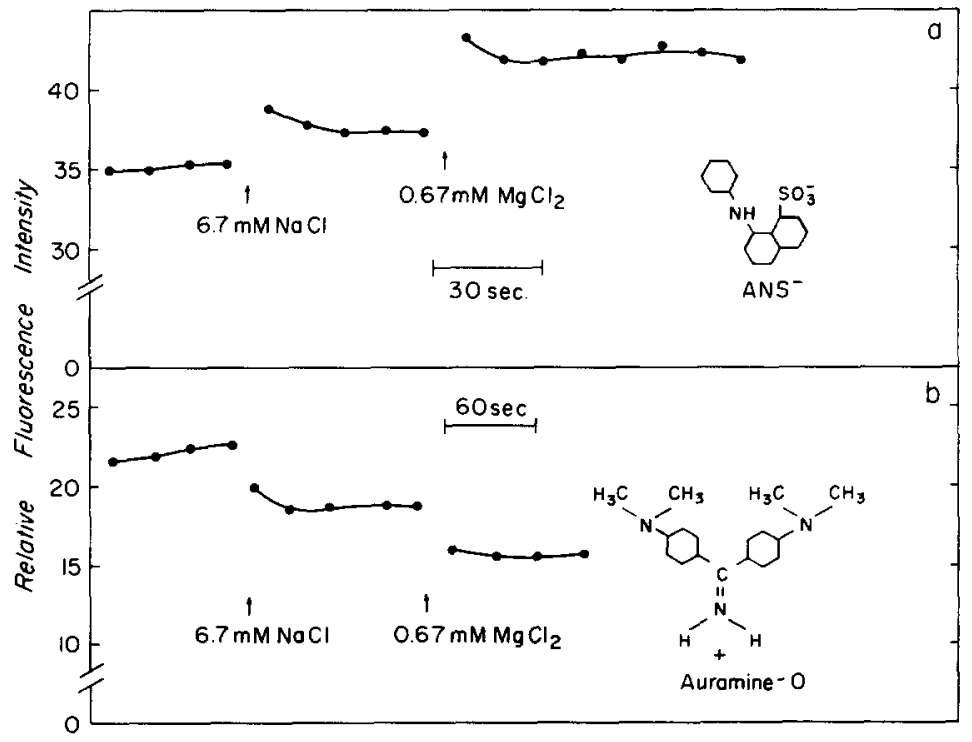

Fig. 4. Time course of cation induced changes in the fluorescence of $\mathrm{ANS}^{-}$(a) and Auramine O (b) in washed spinach chloroplasts. Probe concentration, $5 \mu \mathrm{M} ; 5 \mu \mathrm{g}$ chlorophyll $/ \mathrm{ml}$ suspended in low salt buffer plus $7.5 \mu \mathrm{M}$ DCMU. Corning C.S. 3-72 filter before the emission monochromator. Baseline taken at level of scattering minus probe. 
the fluorescent probe Auramine $\mathrm{O}$ as shown in Fig. 4b. Fluorescence probes are known to reflect rather local events (within a radius $\leqq 20-30 \AA$ ) of their immediate environment [18]; it is probable that the observed changes (Fig. 4) represent the binding of the cation to sites on the membrane surface. This binding could then trigger any slower structural alterations related to spillover, perhaps involving conformational changes in a critical chlorophyll protein matrix (see Discussion).

As with ANS $^{-}$, changes in NPN fluorescence proceed in the same direction for both mono- and divalent cations (Fig. 5). Recalling that NPN is buried further in the

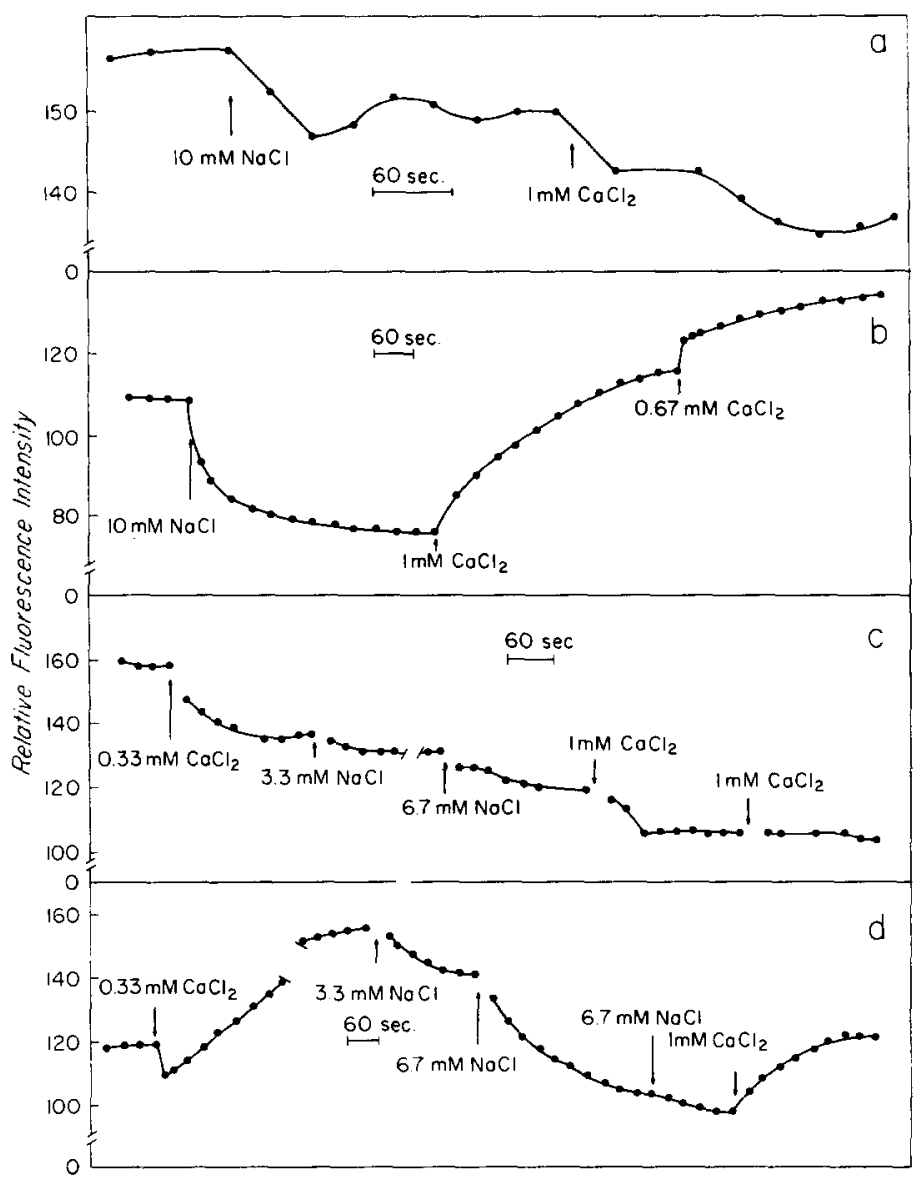

Fig. 5. Time course of cation induced changes in fluorescence of NPN (a, c) and chlorophyll (b, d) in washed oat chloroplasts. Probe concentration, $25 \mu \mathrm{M}$; other conditions as in Fig. 4.

membrane than $\mathrm{ANS}^{-}$, and noting that kinetics of its response to cations are slower than for $\mathrm{ANS}^{-}$, we suggest that the NPN molecules are responding to some structural rearrangement within the membrane, perhaps more closely related to that reported by chlorophyll $a$ fluorescence.

(3) $90^{\circ}$ light scattering

Data of Mohanty et al. [2] suggest that some type of structural event is involved 
in cation induced changes of "long term" chlorophyll $a$ fluorescence, as shown by experiments with glutaraldehyde fixed chloroplasts. It has been demonstrated (see Packer and Murakami [3]) that such treatment stabilizes changes in $90^{\circ}$ light scattering. Thus, we investigated this parameter more fully in the washed chloroplast system. The effects of $\mathrm{NaCl}$ and $\mathrm{CaCl}_{2}$ on steady-state chlorophyll $a$ fluorescence and $90^{\circ}$ light scattering at $540 \mathrm{~nm}$ are shown in Fig. 6 for spinach and oats. Data obtained using peas and lettuce are essentially identical to the results for oats in Fig. 6, for

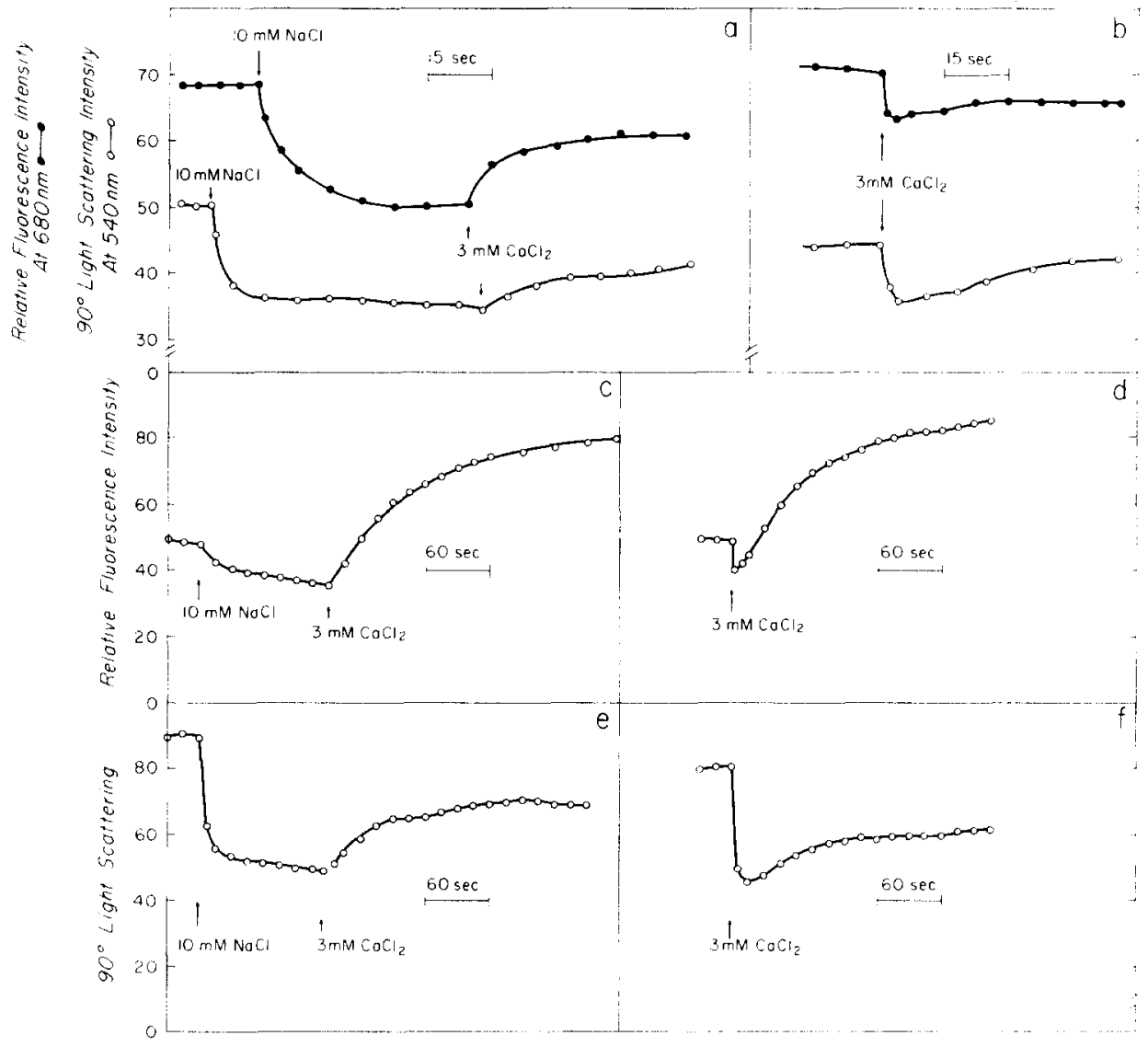

Fig. 6. Time course of cation induced changes in chlorophyll fluorescence and $90^{\circ}$ light scattering in washed spinach chloroplasts (a, b) and in washed oat chloroplasts (c, d, e, f). Chloroplasts containing 8-10 $\mu \mathrm{g}$ chlorophyll $/ \mathrm{ml}$ were suspended in low salt buffer. (see Experimental Methods.)

both chlorophyll $a$ fluorescence and $90^{\circ}$ light scattering. Also, qualitatively, the same situation was found when light at $345,400,450$ and $500 \mathrm{~nm}$ was used to monitor the scattering change (data not shown here). The light scattering responses for all species tested were basically the same, in contrast to the apparent differences (especially in the extent of response to $\mathrm{Ca}^{2+}$ ) in chlorophyll $a$ fluorescence. Furthermore, the kinetics for the $\mathrm{Na}^{+}$induced decrease in light scattering were in all cases faster than the corresponding depression in chlorophyll $a$ fluorescence. 
DISCUSSION

Divalent cation induced increases in $90^{\circ}$ light scattering have been correlated with a decrease in volume (grana shrinkage) in chloroplast suspensions, by means of a non osmotic mechanism [20-22]. In those experiments, no precaution was taken to prepare the samples in low ionic strength; thus, we cannot compare this data directly with the salt induced changes presented here.

Mohanty et al. [2], based on their experiments and the data of others, already suggested that the macroscopic chloroplast changes do not regulate (directly) the fluorescence yield. Considering our experiments comparing the responses of chlorophyll $a$ fluorescence with light scattering in washed chloroplasts to cations, one can see that the larger scale structural phenomena (membrane thickness, volume changes) are not directly responsible for spillover events.

Rather than postulate the alteration of the "proximity of pigments to reaction centers" [23] (also see Murata [24]), which might be expected to follow from changes in thylakoid thickness, our data can be naturally reconciled with a model for energy transfer as described by Seely [12], including the differences seen with spinach as compared with the other species. (However, other explanations are certainly not ruled out as yet). The mutual orientations of the transition moment vectors of the various chlorophyll molecules determine the efficiency and direction of excitation energy migration. Seely [12] demonstrated that the rate of channeling of excitation energy between Photosystems I and II can be governed by the proper orientation of only a small number (six, in a photosynthetic unit containing 344 chlorophylls) of chlorophylls, located in a strategic position between the two photosystems (termed "Sets 13 and 14" in Seely's scheme). In this "transfer switch" region, differences in the specific composition and arrangement of the chlorophylls embedded in the surrounding lipoprotein matrix could explain the species-dependent variation in the response of the chlorophyll fluorescence to the binding of cations. In oats, peas and lettuce, an alteration in conformation of some chlorophyll-protein complex could be activated by cations, allowing a reversible, "bi-modal" change in the average directionality of the crucial transition moment vectors determining spillover: monovalent cations toward a higher spillover state and divalent cations toward a lower spillover state (the latter seen regardless of the presence of monovalent salts). Spinach, on the other hand, is suggested to be unable to be driven further to a lower spillover state; only when $\mathrm{Na}^{+}$"drives" the system toward a higher spillover conformation does $\mathrm{Ca}^{2+}$ act in partially reversing that change in the distribution of intersystem excitation energy.

In support of this interpretation we note that specific, reversible $\mathrm{H}^{+}$and cation induced changes in the states of aggregation of various proteins have been monitored $[25,26]$. On this basis, it can be envisioned that mono- and divalent cations bind to specific sites on one or more large chlorophyll-protein complexes in the "switch" region of the membrane; this then triggers a rearrangement (of "subunits") of conformation which in turn shifts the orientation of the transition moment vectors of the crucial chlorophylls. The study on $\mathrm{Ca}^{2+}$ binding to pigment-protein complexes in chloroplasts as related to chlorophyll $a$ fluorescence changes reported by Davis and Gross [27] may prove to be interesting in this regard. Although, not specifically correlated with any alteration of conformation responsible for the spillover phenomena, the NPN fluorescent probe data is consistent with the idea of these kinds of 
local structural changes occurring within the thylakoid membrane as a response to the action of cations. The integrity of this hypothesis clearly needs further testing, as well as more specific information about the structure of the photosynthetic membrane. (We refer the reader to the recent work of Marsho and Kok [28] for other experiments related to the regulation of photosynthesis by cations in spinach chloroplasts.)

\section{ACKNOWLEDGEMENT}

This research was supported in part by a predoctoral traineeship from N.I.H. (HEW PHS GM00720).

\section{REFERENCES}

1 Gross, E. L. and Hess, S. C. (1973) Arch. Biochem. Biophys. 159, 832-836

2 Mohanty, P., Braun, B. Z. and Govindjee (1973) Biochim. Biophys. Acta 292, 459-476

3 Packer, L. and Murakami, S. (1972) Methods in Enzymology (San Pietro, A., ed.), Vol. 24B, pp. 181-205, Academic Press, New York

4 Murakami, S. and Packer, L. (1970) J. Cell Biol. 47, 332-351

5 Radda, G. K. and Vanderkooi, J. (1972) Biochim. Biophys. Acta 265, 509-549

6 Gulik-Krzwicki, F., Schechter, E., Iwatsubo, M., Rauck, J. L. and Luzzati, V. (1970) Biochim. Biophys. Acta 219, 1-10

7 Lesslauer, W., Cain, J and Blasie, J. K. (1971) Biochim. Biophys. Acta 241, 547-566

8 Zingsheim, H. and Haydon, D. A. (1973) Biochim. Biophys. Acta 298, 755-768

9 Rubalcava, B., deMunoz, D. M. and Gitler, C. (1969) Biochemistry 8, 2742-2747

10 Vanderkooi, J. and Martonosi, A. (1969) Arch. Biochem. Biophys. 133, 153-163

11 Träuble, H. and Overath, P. (1973) Biochim. Biophys. Acta 307, 491-512

12 Seely, G. R. (1973) J. Theor. Biol. 40, 189-199

13 Gross, E. L. (1971) Arch. Biochem. Biophys. 147, 77-84

14 Mackinney, G. (1941) J. Biol. Chem. 140, 315-322

15 Chignell, C. F. (1972) Methods in Pharmacology (Chignell, C. F., ed.), Vol. 2, pp. 33-61, Appelton-Century-Crofts, New York

16 Munday, J. C. and Govindjee (1969) Biophys. J. 9, 1-21

17 Govindjee and Papageorgiou, G. (1971) Photophysiology (Giese, A. C., ed.), Vol. 6, pp. 1-46, Academic Press, New York

18 Weber, G. (1970) Spectroscopic Approaches to Biomolecular Conformation (Urry, D. W., ed.), pp. 23-31, American Medical Association, Chicago

19 Radda, G. K. (1971) Curr. Top. Bioenerg. 4, 81-126

20 Dilley, R. A. and Rothstein, A. (1967) Biochim. Biophys. Acta 135, 427-443

21 Brown, A. P. (1967) Biochem. J. 102, 791-800

22 Gross, E. and Packer, L. (1967) Arch. Biochem. Biophys. 121, 779-789

23 Bonaventura, C. and Myers, J. (1969) Biochim. Biophys. Acta 189, 366-383

24 Murata, N. (1971) Biochim. Biophys. Acta 245, 365-372

25 Anderson, S. R. and Weber, G. (1969) Biochemistry 8, 371-377

26 Stadtman, E. R., Shapiro, B. M., Kingdon, H. S., Woolfolk, C. A. and Hubbard, J. S. (1968) Adv. Enzyme Regul. 6, 257-289

27 Davis, D. J. and Gross, E. Z. (1974) Fed. Proc. 33, 1255

28 Marsho, T. V. and Kok, B. (1974) Biochim. Biophys. Acta 333, 353-365 